\title{
Looking at the Impact of the Flipped Classroom Model on Reading Comprehension of Iranian EFL Learners
}

\author{
Sahar Lotfi Sin, Hossein Siahpoosh \\ Department of English Language, Ardabil Branch, Islamic Azad University, Ardabil, Iran \\ Email address: \\ lotfiseen.sahar@gmail.com (S. L. Sin), siahpoosh_hossein@yahoo.com (H. Siahpoosh)

\section{To cite this article:} \\ Sahar Lotfi Sin, Hossein Siahpoosh. Looking at the Impact of the Flipped Classroom Model on Reading Comprehension of Iranian EFL \\ Learners. Arabic Language, Literature \& Culture. Vol. 5, No. 2, 2020, pp. 14-22. doi: 10.11648/j.allc.20200502.12
}

Received: January 26, 2020; Accepted: July 3, 2020; Published: July 17, 2020

\begin{abstract}
The flipped classroom instruction has been the focus of many researchers. It needs a lot of preparation and technological tools and many have tried it in different ways to teach different subjects with different grades. This study utilized to investigate the effect of flipped classroom on reading comprehension of Iranian EFL learners with different proficiency level (elementary and intermediate). So, 120 participants were selected based on their performance on Oxford Placement Test, then 60 participants for intermediate and 60 for elementary level were selected and a Nelson and PET reading test were submitted for their homogeneity. The Oxford Placement Test (OPT) was administered to 200 students in order to select 120 subjects to participate in the main study. In this experimental research, the effect of flipped classroom on reading comprehension is measured therefore, flipped classroom is the independent variable and reading comprehension is the dependent variable. The result of the posttest showed a statistically significant point of preference for the experimental group over the control group in reading comprehension for both of elementary and intermediate levels. The findings showed that the students who received instruction through flipped classrooms had better performance compared to those who were trained through traditional classrooms.
\end{abstract}

Keywords: Reading Comprehension, Flipping Class, PET Reading Test

\section{Introduction}

Reading plays a pivotal role in language learning and is an essential skill for successful functioning of EFL learners in the tertiary level of education [26]. Reading comprehension is a complex process between identifying printed symbols and interpreting the meaning behind the symbols. Some factors affect reading comprehension skill such as complexity of the reading text, environmental influences, anxiety during reading comprehension, interest and motivation, decoding or word recognition speed, and medical problems. One of the newest trends which is set to assume to have an impact on reading comprehension in language learning is flipped instructional strategy.

Flipped model of instruction is a relatively new teaching strategy attempting to move the lecture outside of class, usually delivered through some electronic means, and transferring the application assignments, formerly homework, into the classroom [11]. The main focus of this strategy is to expand students' engagement, fortifying of group-based aptitudes, personalized student guidance, classroom discussion, and creative freedom of faculty while maintaining a standardized module [24]. Using this inductive approach, Tucker [34] stated class becomes the place to "work through problems, advance concepts, and engage in collaborative learning" (p. 82). Such use of class time could potentially provide students with the opportunity to learn how to think for themselves by being actively engaged in the learning content. The flipped classroom model frees up class time by moving instruction from class to home so that the teacher is able to supervise collaborative learning experiences [30].

The flipped classroom (also referred to as the inverted classroom) provides students with audio and video lectures that can be accessed from home and paired with collaborative, student-centered activities during class time to aid mastery of concepts and skills $[5,14,17]$. The flipped classroom design assigns video/audio lectures for homework to replace the instructional lectures that traditionally take place during class time. During class time, teachers provide students with the opportunity to practice and explore new concepts and skills 
through engaging, student-centered activities that focus on skill application and productive collaboration [5, 14, 17].

In elementary level there's a lot going on in reading, from letter and word recognition to understanding meaning at the phrase, sentence, and paragraph level. When the readers encounter vocabulary, they do not know or do not recognize due to inaccurate decoding, they are likely to skip ahead. The more blanks in a line of text, the harder it is to make meaning and the more cognitively challenging and frustrating the reading task becomes.

In intermediate level learners face the difficulty to understand complex sentences in reading comprehension. Complex sentences are sentences that consist of several clauses, and at times contain conjunctions such as although, because, furthermore, and however. Other causes of difficulties in reading comprehension among learners include coordinating conjunctions, prepositional phrases, participial phrases, and nominalizations. They cause a lot of difficulties in reading comprehension because they make the writings more complex and difficult to comprehend.

The present study attempts to investigate the effect of flipped techniques on EFL learners' reading comprehension based on their proficiency level.

Considering the objective of the study, the following research questions are formulated:

Q1. Does flipped classroom have any significant effect on Iranian EFL learners' reading comprehension at elementary level?

Q2. Does flipped classroom have any significant effect on Iranian EFL learners' reading comprehension at intermediate level?

Q3. Does flipped classroom have the same effect on elementary and intermediate levels EFL learners' reading comprehension?

\section{Literature Review}

Flipped learning can be considered more of a complement, rather than a substitute, to the traditional classroom because it allows classroom time to be geared more toward active and collaborative learning. Reading comprehension is a skill that affects learning in all content areas, and, therefore, must be fostered in the most effective manner across disciplines. In using different strategies in order to teach the same content, actually it aims to determine whether the traditional or the flipped method results in a statistically significant improvement in students' achievement. The overarching aim of this study is to analyze what advantages can be gained through utilizing the flipped classroom method, as well as review what disadvantages the method might have.

The main focus of this strategy is to expand students' engagement, fortifying of group-based aptitudes, personalized student guidance, classroom discussion, and creative freedom of faculty while maintaining a standardized module [24]. Using this inductive approach, Tucker [34] stated class becomes the place to "work through problems, advance concepts, and engage in collaborative learning" (p.
82). Such use of class time could potentially provide students with the opportunity to learn how to think for themselves by being actively engaged in the learning content.

According to Baker [3], the delivery of the "lecture" prior to coming to class is the first step in the flipped classroom model. In class, students are prepared to take part in the collaborative situation the teacher has designed because the background knowledge has been created before the class. In 2010, Cherry suggested that blended learning involves a shift in strategy in three areas: from teacher-centered to studentcentered learning, from limited to high interactions between students and resources. The concept is gaining popularity, due to the widespread use of technology in education which provide the opportunity for teachers to accomplish the flip such as iTunes, YouTube, and Learning Management Systems (LMS).

Instructors of all kinds tout the benefits of the flipped model, including efficient use of class time [8], more active learning opportunities for students $[16,2]$, more interaction between student and teacher [22]. Moreover, Finkel [12] notes that Flipped Classrooms allow students to move at their own pace, access instruction at any time, benefit from better used classroom time, and etc. According to Boucher, Robertson, Wainner, and Sanders [6], the issue of using time differently in this model is associated with many potential benefits: having more time for interaction and clarification, more time to understand concepts deeply, and more time for additional learning purposes. Another often cited merits of flipped classrooms have been presented by Educause [11] who believed that such classrooms bring a change in emphasis from instructor responsibility for student learning to increased student responsibility. In fact, students in this model generally have a more active role and ultimate responsibility for their learning [15]. Indubitably students would be able to direct their own learning in the very near future. Flipping the classroom can help students learn to take more responsibility for their own learning [23, 37].

Meanwhile, not all teachers who flip find success and there are critics to this approach. Milman [25] notes several concerns with the Flipped Classroom, such as poor-quality video production, conditions in which the students view the video, inability to monitor comprehension and provide justin-time information when needed, and use with second language learners or students with learning disabilities. Moreover, teachers concern that their role will be diminished, the students engage with the out-of-class instruction will not be interactive anymore, a lack of responsibility for students to complete the out-of-class instruction, and more cost and time needed to create instructional materials.

Comprehension of the text is the main goal of the readers. [27] stated that comprehension in reading is the understanding that one acquires from text. It is the process in which meaning is constructed and is a main goal of reading instruction for students. According to [33], reading comprehension means understanding what has been read. It is an active thinking process that depends not only on comprehension skill but also students`experience, and prior 
knowledge comprehension involves understanding the vocabulary seeing the relationship among words and concepts, organizing ideas, recognizing author's making judgment, and evaluating. Along the same line, reading comprehension is defined as the ability to communicate a text leading to an integrated process that involves decoding vocabulary and sentences, employing prior knowledge relevant to the text and using cognitive and meta-cognitive strategies in order to make sense and to get the target message the author wants to convey.

It is clear that prior knowledge, meaning and cognitive strategies are core words in the previously mentioned definitions [1]. To sum up, simple comprehension of meaning of words is not sufficient to comprehend a text while reading. To achieve comprehension in reading, effective readers need to implement such practices as relating their background experience with the text, summarizing information, drawing conclusions, and posing questions at the text [21]. Kirmizi [21] confirmed that comprehension involves constructing meaning that is reasonable and accurate by connecting what has been read to what the reader already knows and thinks about all of this information until it is understood. Comprehension is the final goal of reading instruction.

Many definitions of reading comprehension have been suggested, the definition we have adopted for purposes of discussing reading comprehension research reflects an interactive view of reading in which "reading is the process of constructing meaning through the dynamic interaction among the reader's existing knowledge, the information suggested by the written language, and the context of the reading situation." This definition was proposed by Wixson and Peters [35].

Over the past decades, the increasing use of Computer Assisted Language Learning (CALL) has encouraged numerous studies investigating the impact of the implementation of technology on students' language learning outcomes and their motivation for learning. A number of studies state that CALL improves learners' linguistic proficiency, communicative competence and learner autonomy because it has flexible access, and allows learners to adjust their own learning paces and therefore increases learning motivation and self-confidence [29, 13]. Furthermore, the flipped classroom, an approach that utilizes CALL to snapshot the essence of lectures and uploads the videos online, allowing students to have flexible access and to choose their own pace of learning, has gained in popularity over the past 5 years [18]. Some preliminary data suggest that flipped classrooms may produce benefits such as increasing test scores, and improving students' learning attitudes, as well as providing in valuable benefits for students with special needs (Flipped Learning Network).

Finkel's [12] study about mathematics and at risk ninth grade students in Michigan, showed that a flipped classroom reduces the students' failure to learn. In addition, flipped classroom advocates proclaim that this practice enhances teacher- student interaction, provides a student-centered learning environment, increases students' engagements in class because it "speaks the language of today's students" [4]. Students today commonly turn to the web and social media for information and communication, and the use of short videos may therefore prompt students' learning engagement and improve their learning outcome in English. Also, a recent study [20] has shown the effect of a researcher-developed learning game on motivating EFL learners to persevere in completing learning-by-playing tasks, while also reducing their English anxiety.

The "flipped classroom" is a new catch phrase in education, but it is not a completely novel idea. Teachers often assign reading to be done at home, and then expect students to engage in conversation about the reading in class. This design could be classified as an inverted classroom [31]. However, a few key characteristics distinguish the flipped classroom from an inverted classroom. In the flipped classroom, students watch video-recorded lectures outside of class, thus increasing time for active learning and practice to occur in the class [31]. While implementation of this method may look slightly different for each teacher, essentially "the 'flipped' part of the flipped classroom means students watch or listen to lessons at home and do their 'homework' in the class" [14].

The following points should be recognized as the undoubted advantage of this method: First point - increasing the contact time between the teacher and the student; i.e. it is practically doubled. In the framework of the traditional method the student listens to the theory in the classroom and does the homework at home, but teacher does not always possess free time to check it in the classroom. As for the flipped classroom system, all the student's doubts and his mistakes can be corrected in the classroom together with the teacher. Second point - personalized approach to each student, third point - an opportunity for the teacher to create authentic mini lectures. Anyone will probably agree that there is no perfect tutorial explaining this or that language subject. With mini lectures the teacher can create a unique authentic short film, where the information will be handled and chosen in the most perfect way, taking into account the professional orientation, age features and other important factors in the learning group. Fourth point - increasing the responsibility and autonomy of the learner. The student is aware of the need to dedicate some time listening to the training video that is a more attractive, more spectacular, more habitual activity; it immerses the student in a more common for the majority of young people computing environment.

The flipped classroom technology fulfills the primary task - to promote the growth of student autonomy and improve the quality of this autonomy as much as possible, to teach him to make decisions about what, how and when to study. This means two things: "to be able to learn" and have the necessary didactic material.

\section{Methodology}

This study is an attempt to explore the effect of flipped 
classroom on the reading comprehension of EFL learners. By defining flipped classroom and its importance in learning, it is believed that this could be the most suitable and successful technique in Iran, to overcome the mismatches between teaching and learning them by individuals to cause autonomy and improvement in their reading comprehension. To prove this claim in the following parts, some variable, such as the participants, instrumentation, procedure, design of the study will be explained. Then, the procedures of data collection and the scoring method will be explained.

\subsection{Participants}

The population of the research was 450 female learners in Paniz institute, Ardebil, Iran. Then 200 participants were randomly chosen out of the population and according to their performance on oxford placement test, 120 participants were selected ( 60 for elementary and 60 for intermediate level). It is worth mentioning scores between $0-17$ was for elementary level and scores between 30-39 determined as intermediate. Sixty elementary participants were randomly divided in two groups (30 participants as control group and 30 as experimental group) and the same process is done for intermediate level too. Individuals' ages ranged between 1225 and all of them were female students in Ardebil city.

\subsection{Instruments}

\subsubsection{Oxford Placement Test}

The initial instrument utilized in this study was the oxford placement test to find out about the proficiency levels of the participants for the study. This test was used in order to match the participants in terms of their proficiency in all groups under investigation and to examine participants' achievement in reading comprehension before any specific instruction of flipped approach. This test is designed and established by the Language Center at Oxford University and consisted of listening and grammar and reading comprehension sections. The listening section consisted of 100 items. It took approximately ten minutes to complete the listening test. Test-takers were asked to choose the correct word which they heard in short sentences from two choices. Buck (2001) called this type of test a phonemic discrimination task in which the test-takers' task is to distinguish two words which differ by one phoneme. The grammar section consisted of 100 items. Fifty minutes were allotted for completion. Test-takers were asked to read the stem with a blank and to choose one of the three options for the blank, the test type is a multiple-choice task (Purpura, 2013). The reading comprehension section consists of 60 multiple-choice items. It took about fifty minutes.

\subsubsection{Nelson Reading Comprehension Test}

The Nelson-Denny Reading Test was created in 1929 by M. S. Nelson and E. C. Denny, both of whom were on the faculty of Iowa State Teacher's College. The purpose of the test is to measure reading ability among high school and college students. The Nelson test included two subtests. The first subtest was for Vocabulary and the second subtest for reading comprehension. The second subtest, Comprehension, required examinees to read seven short passages (also drawn from high school and college textbooks) and to respond to 35 multiple-choice questions about the contents of these passages. Approximately half of these items related to specific factual content, while the other half are more inferential in nature. The primary uses of the Nelson were as a screening test for reading problems, as a predictor of academic success, and as a measure of progress resulting from educational interventions. These functions overlap to some degree. This test will be used as pretest.

\subsubsection{PET Reading Comprehension Test}

The Preliminary English Test (PET), is an English language examination provided by Cambridge Assessment English (previously known as Cambridge English Language Assessment and University of Cambridge ESOL examinations) was first launched in 1943. Its reading comprehension test included 35 questions, 10 multiple choice question and 5 matching questions and 10 fill in the blank questions and 10 reading comprehension questions.

\subsubsection{Reading Comprehension Test (post-test)}

The participants in all experimental and control groups were given a reading comprehension test as posttest based on their proficiency level (intermediate \&elementary). In order to evaluate the elementary participants' reading comprehension, they will be given a 30 multiple choice item reading comprehension test as post-test based on "Select Readings" book, at first the test was piloted and then was given to the participants selected after the pre-test. The reading comprehension test was piloted among 30 students with the same characteristics (age, gender, level) for the purpose of calculating the reliability of the test.

Intermediate Participants were given a 40 multiple choice item test based on "Select Readings" book. One point was allocated to each correct response which was answered by the participants correctly. The test was first piloted and it was given to the 30 participants that are selected after the pre-test of language proficiency. This test takes around 40 minutes for the learners to answer. Following the twelve treatment sessions based on an appropriate lesson plan, this reading comprehension test was used as the posttest of the study.

\subsection{Procedure}

The population of the research was 450 learners in Paniz institute, Ardebil, Iran. Then 200 participants were randomly selected out of the population and according to their performance on oxford placement test, 120 participants were selected (60 for elementary and 60 for intermediate level). It is worth mentioning scores between 0-17 was for elementary level and scores between 30-39 determined as intermediate. Sixty elementary participants were randomly divided in two groups (as control and experimental group) and the same process was done for intermediate level too. Individuals' ages range between 12-25. The current study is true- experimental, quantitative research with pre-test and post-test which is carried out by two groups, namely, the experimental and 
control groups. A true-experiment is an empirical interventional study used to estimate the causal impact of an intervention on its target population with random assignment. Although the independent variable is manipulated, participants are randomly assigned to conditions or orders of conditions [9].

It aims at predicting the outcome by introducing a change of the preconditions, which is represented by one or more independent variables, also referred to as "input variables" or "predictor variables." The change in one or more independent variables is generally hypothesized to result in a change in one or more dependent variables, also referred to as "output variables" or "response variables." The experimental design may also identify control variables that must be held constant to prevent external factors from affecting the results. Experimental design involves not only the selection of suitable independent, dependent, and control variables, but planning the 72 delivery of the experiment under statistically optimal conditions given the constraints of available resources. It is often conducted to evaluate the effectiveness of a treatment-perhaps a type of psychotherapy or an educational intervention. In this experimental research, the effect of flipped classroom on reading comprehension is measured therefore, flipped classroom is the independent variable and reading comprehension is the dependent variable.

\section{Results}

The Oxford Placement Test (OPT) was administered to 200 students in order to select 120 subjects to participate in the main study. The participants whose scores on the OPT were zero to 17 formed the elementary group; and those whose scores were between 30 and 39 were selected for the intermediate level. The KR-21 reliability index for the OPT was .93 (Table 1). It should also be noted that the distribution of scores on the OPT met the normality assumption. The ratios of skewness and kurtosis over their standard errors were lower than $+/-1.96$.

Table 1. Descriptive statistics; Oxford Placement Test (Subject Selection Phases of Study).

\begin{tabular}{|c|c|c|c|c|c|c|c|c|c|}
\hline & $\mathbf{N}$ & Min & Max & Std. Deviation & Variance & Skewness & & Kurtosis & \\
\hline & & & & & & Statistic & Std. Error & Statistics & Std. Error \\
\hline OPT & 200 & 1 & 60 & 13.498 & 181.778 & .202 & .172 & & .342 \\
\hline KR-21 & .93 & & & & & Ratio. & 1.18 & & -1.89 \\
\hline
\end{tabular}

The reading section of the PET test was piloted on a group of 30 students in order to compute its item facility and item discrimination indices. Table 2 displays the item facility (IF) and item discrimination (ID) indices. All IF indices were between .37 and .63 except for items 12 and 22 whose indices were slightly lower than .37 . The discrimination indices were all higher than .40 except for item 12,15 and 22.
These items were revised for the main study.

Table 2 displays the descriptive statistics and KR-21 reliability of piloting PET for elementary group. The KR-21 reliability for the PET test was .91. It should also be noted that the distribution of scores on the PET met the normality assumption. The ratios of skewness and kurtosis over their standard errors were lower than $+/-1.96$.

Table 2. Descriptive Statistics Piloting PET Test (Elementary Groups).

\begin{tabular}{|c|c|c|c|c|c|c|c|c|c|}
\hline & $\mathbf{N}$ & Min & $\operatorname{Max}$ & Std. Deviation & Variance & Skewness & & Kurtosis & \\
\hline & & & & & & Statistic & Std. Error & Statistics & Std. Error \\
\hline PET & 30 & 4 & 29 & 16.67 & 46.299 & .128 & -.427 & -.543 & .833 \\
\hline KR-21 &. .91 & & & & & Ratio. & .299 & Ratio & -.651 \\
\hline
\end{tabular}

The reading section of the NELSON test was piloted on a group of 30 students in order to compute its item facility and item discrimination indices. All IF indices were between .37 and .63 except for items 31,34 and 36 whose indices were slightly lower than .37 . The discrimination indices were all higher than .40 except for item 30, 31, 34 and 36. These items were revised for the main study.
Table 3 displays the descriptive statistics and KR-21 reliability of piloting NELSON for intermediate group. The KR-21 reliability for the NELSON test was .88. It should also be noted that the distribution of scores on the NELSON met the normality assumption. The ratios of skewness and kurtosis over their standard errors were lower than +/- 1.96.

Table 3. Descriptive Statistics Piloting PET Test (Intermediate Groups).

\begin{tabular}{|c|c|c|c|c|c|c|c|c|c|}
\hline & $\mathbf{N}$ & Min & $\operatorname{Max}$ & Std. Deviation & Variance & Skewness & & Kurtosis & \\
\hline & & & & & & Statistic & Std. Error & Statistics & Std. Error \\
\hline $\begin{array}{l}\text { NELSON } \\
\text { KR-21 }\end{array}$ & $\begin{array}{l}30 \\
.88\end{array}$ & 9 & 38 & 23.37 & 69.964 & $\begin{array}{l}-.042 \\
\text { Ratio. }\end{array}$ & $\begin{array}{l}-.427 \\
.299\end{array}$ & $\begin{array}{l}-1.034 \\
\text { Ratio }\end{array}$ & $\begin{array}{l}.833 \\
-1.24\end{array}$ \\
\hline
\end{tabular}

Also, the assumption of normality was also retained because the absolute values of the ratios of skewness and kurtosis over their standard errors were lower than 1.96.

An independent t-test was run to compare the elementary experimental and control groups' means on the pretest of reading comprehension in order to prove that they enjoyed the same levels of reading comprehension ability prior to the administration of treatments. Based on the results it can be 
claimed that the elementary experimental $(\mathrm{M}=15.14, \mathrm{SD}=$ $4.68)$ and control $(\mathrm{M}=15.12, \mathrm{SD}=4.99)$ groups had almost the same means on the pretest of reading comprehension.

The results of the independent t-test $(\mathrm{t}(52)=.021, \mathrm{p}>.05$, $95 \%$ CI [-2.61, 2.67], Cohen's $d=.004$ representing a weak effect size) (Table 4) indicated that there was not any significant difference between the two groups' mean scores on the pretest of reading comprehension. Thus, it can be claimed that they enjoyed the same level of reading comprehension ability prior to the main study.

The negative 95\% lower bound confidence interval of 2.61 indicated that the difference between the two groups' means on the pretest could have been zero. Thus, the abovementioned conclusion as no significant difference between the two groups' means was correctly made. It should also be noted that the assumption of homogeneity of variances was met (Levene's $F=.001, p>.05$ ). That is why the first row of Table 4, i.e. "Equal variances assumed" was reported.

Table 4. Independent Sample t-test: Pretest of Reading Comprehension by Group (Elementary Level).

\begin{tabular}{|c|c|c|c|c|c|c|c|c|c|}
\hline & \multicolumn{5}{|c|}{ Leven's Test for Equality of Variances } & \multicolumn{4}{|c|}{ t-test for Equality of Means } \\
\hline & \multirow{2}{*}{$\mathbf{F}$} & \multirow{2}{*}{ Sig. } & \multirow{2}{*}{$\mathbf{T}$} & \multirow{2}{*}{ df } & \multirow{2}{*}{ Sig.(2-tailed) } & \multirow{2}{*}{$\begin{array}{l}\text { Mean } \\
\text { Difference }\end{array}$} & \multirow{2}{*}{$\begin{array}{l}\text { Std. Error } \\
\text { Differences }\end{array}$} & \multicolumn{2}{|c|}{ 95\% Confidence Interval of the Difference } \\
\hline & & & & & & & & Lower & Upper \\
\hline Equal Variances assumed & .001 & .974 & .021 & 52 & .983 & .027 & 1.317 & -2.615 & 2.670 \\
\hline Equal Variances not assumed & & & & 51.031 & .983 & .027 & 1.320 & -2.623 & 2.678 \\
\hline
\end{tabular}

The results of the independent t-test $(\mathrm{t}(53)=.189, \mathrm{p}>.05$, $95 \%$ CI $[-3.15,3.81]$, Cohen's $d=.051$ representing a weak effect size) (Table 5) indicated that there was not any significant difference between the two groups' mean scores on the pretest of reading comprehension. Thus it can be claimed that they enjoyed the same level of reading comprehension ability prior to the main study.

The negative 95\% lower bound confidence interval of -
3.15 indicated that the difference between the two groups' means on the pretest could have been zero. Thus the above mentioned conclusion as no significant difference between the two groups' means was correctly made. It should also be noted that the assumption of homogeneity of variances was met (Levene's $\mathrm{F}=.031, \mathrm{p}>.05$ ). That is why the first row of Table 5, i.e. "Equal variances assumed" was reported.

Table 5. Independent Sample t-test: Pretest of Reading Comprehension by Group (Intermediate Level).

\begin{tabular}{llllllllll}
\hline & \multicolumn{3}{l}{ Leven's Test for Equality of Variances } & \multicolumn{2}{l}{ t-test for Equality of Means } \\
\cline { 2 - 9 } & F & Sig. & T & df & Sig.(2-tailed) & $\begin{array}{l}\text { Mean } \\
\text { Difference }\end{array}$ & $\begin{array}{l}\text { Std. Error } \\
\text { Differences }\end{array}$ & $\begin{array}{l}\text { 95\% Confidence Interval of the Difference } \\
\text { Lower }\end{array}$ \\
\hline Equal Variances assumed & .031 & .860 & .189 & 53 & .983 & .329 & 1.738 & -3.157 \\
Equal Variances not assumed & & & .190 & 52.930 & .983 & .329 & 1.738 & -3.156 \\
\hline
\end{tabular}

The first null-hypothesis stated that flipped classroom did not have any significant effect on Iranian EFL learners' reading comprehension at elementary level. An independent t-test was run to compare the elementary experimental and control groups' means on the posttest of reading comprehension in order to probe the first null-hypothesis. Based on the results the elementary experimental group ( $\mathrm{M}=$ 23.96, $\mathrm{SD}=4.59$ ) had a higher mean than the control group $(\mathrm{M}=20.73, \mathrm{SD}=4.87)$ on the posttest of reading comprehension.
The results of the independent $\mathrm{t}$-test $(\mathrm{t}(52)=2.50, \mathrm{p}<.05$, $95 \%$ CI [.646, 5.82], Cohen's $\mathrm{d}=.683$ representing a moderate effect size) (Table 6) indicated that the experimental group significantly outperformed the control group on the posttest of reading comprehension. Thus, the first null-hypothesis was rejected.

It should also be noted that the assumption of homogeneity of variances was met (Levene's $\mathrm{F}=.183, \mathrm{p}>.05$ ). That is why the first row of Table 6, i.e. "Equal variances assumed" was reported.

Table 6. Independent Sample t-test; Posttest of Reading Comprehension by Groups (Elementary Level).

\begin{tabular}{|c|c|c|c|c|c|c|c|c|c|}
\hline & \multicolumn{5}{|c|}{ Leven's Test for Equality of Variances } & \multicolumn{2}{|c|}{ t-test for Equality of Means } & \multirow{2}{*}{\multicolumn{2}{|c|}{ 95\% Confidence Interval of the Difference }} \\
\hline & \multirow{2}{*}{$\mathbf{F}$} & \multirow{2}{*}{ Sig. } & \multirow{2}{*}{$\mathbf{T}$} & \multirow{2}{*}{ df } & \multirow{2}{*}{$\begin{array}{l}\text { Sig.(2- } \\
\text { tailed) }\end{array}$} & \multirow{2}{*}{$\begin{array}{l}\text { Mean } \\
\text { Difference }\end{array}$} & \multirow{2}{*}{$\begin{array}{l}\text { Std. Error } \\
\text { Differences }\end{array}$} & & \\
\hline & & & & & & & & Lower & Upper \\
\hline Equal Variances assumed & .183 & .671 & 2.507 & 52 & .015 & 3.234 & 1.290 & .646 & 5.822 \\
\hline Equal Variances not assumed & & & 2.502 & 51.076 & .016 & 3.234 & 1.293 & .639 & 5.828 \\
\hline
\end{tabular}

The second null-hypothesis stated that flipped classroom did not have any significant effect on Iranian EFL learners' reading comprehension at intermediate level. An independent t-test was run to compare the intermediate experimental and control groups' means on the posttest of reading comprehension in order to probe the first null-hypothesis. Based on the results it can be claimed that the intermediate experimental group $(\mathrm{M}=28.07, \mathrm{SD}=6.23)$ had a higher mean than the control group $(\mathrm{M}=20.44, \mathrm{SD}=7.30)$ on the posttest of reading comprehension.

The results of the independent t-test $(\mathrm{t}(53)=4.17, \mathrm{p}<.05$, 95\% CI [3.95, 11.29], Cohen's $d=1.12$ representing a moderate effect size) (Table 7) indicated that the experimental group significantly outperformed the control group on the posttest of reading comprehension. Thus, the second null-hypothesis was rejected.

It should also be noted that the assumption of homogeneity of variances was met (Levene's $F=.366, \mathrm{p}>.05$ ). That is why 
the first row of Table 7, i.e. "Equal variances assumed" was reported.

Table 7. Independent Sample t-test; Posttest of Reading Comprehension by Groups (Intermediate Level).

\begin{tabular}{|c|c|c|c|c|c|c|c|c|c|}
\hline & \multicolumn{5}{|c|}{ Leven's Test for Equality of Variances } & \multicolumn{2}{|c|}{ t-test for Equality of Means } & \multirow{2}{*}{\multicolumn{2}{|c|}{ 95\% Confidence Interval of the Difference }} \\
\hline & $\mathbf{F}$ & Si & $\mathbf{T}$ & df & Sig.(2- & Mean & Std. Error & & \\
\hline & $F$ & sig. & 1 & dit & tailed) & Difference & Differences & Lower & Upper \\
\hline Equal Variances assumed & .366 & .548 & 4.170 & 53 & .000 & 7.627 & 1.829 & 3.959 & 11.295 \\
\hline Equal Variances not assumed & & & 4.158 & 51.060 & .000 & 7.627 & 1.834 & 3.945 & 1.309 \\
\hline
\end{tabular}

The gain scores were computed for the intermediate and elementary groups by subtracting posttest scores from pretest. An independent-samples t-test was run to compare the experimental elementary and intermediate group's means on the gain score in order to probe the third null-hypothesis. Based on the results it can be claimed that the experimental intermediate group $(\mathrm{M}=8.18, \mathrm{SD}=9.81)$ and elementary group $(\mathrm{M}=8.82, \mathrm{SD}=5.14)$ had almost the same means on gain score.

The results of the independent-samples t-test $(\mathrm{t}(40)=.307$, $\mathrm{p}>.05,95 \%$ CI $[-3.58,4.87]$, Cohen's $\mathrm{d}=.085$ representing a WEAK effect size) the result indicated that there was not any significant difference between the intermediate and elementary groups' mean on gain score. Thus, the third nullhypothesis was supported.

It should also be noted that the assumption of homogeneity of variances was not met (Levene's $F=11.25, p<.05$ ). That is why the second row of Table 8, i.e. "Equal variances not assumed" was reported.

Table 8. Independent-Samples t-test; Gain Score by Proficiency Levels (Experimental Group).

\begin{tabular}{|c|c|c|c|c|c|c|c|c|c|}
\hline & \multicolumn{5}{|c|}{ Leven's Test for Equality of Variances } & \multicolumn{4}{|c|}{ t-test for Equality of Means } \\
\hline & \multirow{2}{*}{$\mathbf{F}$} & \multirow{2}{*}{ Sig. } & \multirow{2}{*}{$T$} & \multirow{2}{*}{ df } & \multirow{2}{*}{$\begin{array}{l}\text { Sig.(2- } \\
\text { tailed) }\end{array}$} & \multirow{2}{*}{$\begin{array}{l}\text { Mean } \\
\text { Difference }\end{array}$} & \multirow{2}{*}{$\begin{array}{l}\text { Std. Error } \\
\text { Differences }\end{array}$} & \multicolumn{2}{|c|}{ 95\% Confidence Interval of the Difference } \\
\hline & & & & & & & & Lower & Upper \\
\hline Equal Variances assumed & 11.251 & .001 & .307 & 54 & .760 & .643 & 2.094 & -3.555 & 4.841 \\
\hline Equal Variances not assumed & & & .307 & 40.791 & .760 & .643 & 2.094 & 3.586 & 4.872 \\
\hline
\end{tabular}

The results statistically revealed that experimental group significantly did better than the control group. Therefore, the null hypotheses of the study "flipped classroom does not have any significant effect on Iranian EFL learners' reading comprehension at elementary level and flipped classroom does not have any significant effect on Iranian EFL learners' reading comprehension at intermediate level" were rejected.

\section{Discussion}

Second language learners struggle to know how to study effectively and made progress in developing their language skills. Some of these learners rely on teachers and others on a structured language program to tell them what to do and how to study in their target language. But good language learners develop language learning skills which enable them to manage their own learning. Through this study, it is found that flipped learning has more effect than traditional learning on reading comprehension of Iranian EFL learners. It was also revealed that there was not significant difference between elementary and intermediate levels.

The cognitive load theory [32] developed in the field of educational psychology supports this claim. According to this theory, learners' "cognitive capacity in working memory is limited, so that if a learning task requires too much capacity, learning will be hampered" [10] (p. 105). Hence, the available knowledge structures in long-term memory, or a large, permanent store of organized information, are essential for preventing working memory overload and for guiding cognitive processes.

Based on the findings of the present study, it can be concluded that the implementing of flipped classrooms in teaching and learning can produce positive results because they could absorb students in learning English. The positive effects of using flipped classrooms became obvious after the treatment. Here, it can be claimed that receiving instruction through using flipped classrooms can facilitate English learning. Flipped classrooms can make the students independent and help them learn how to study out of the classroom. To become self-directed learners, students must learn to assess the demands of the task, evaluate their own knowledge and skills, plan their approach, monitor their progress, and adjust their strategies as needed flipped lecture checks on component skill and gives the opportunities to assess, apply and discuss previously acquired knowledge. Regarding the effectiveness and importance of the flipped classrooms, they are recommended to be implemented in educational environments. In this study, flipped classrooms had some benefits for the students; these benefits may be attributable to the executive guidance based on knowledge schema that was established before class through pre-learning.

To sum up, it can be concluded that flipped instruction in EFL classes will provide positive effects. Moreover, English teacher might find this study helpful as they seek to improve or modify the teaching methods, they use in order to gain the best results in the learning process.

The result of this study showed the effect of flipped classroom on reading comprehension. The Oxford Placement Test and posttest scores included that flipped instruction can be effective in reading comprehension. Language schools and language institutes influences students' future success, it will be great importance for their curriculum designers and authorities to adopt beneficial techniques and effective 
supplementary materials in teaching. They need to provide learners with a more suitable context for long term learning, and as a result to get good reputation of more effective teaching for themselves.

Teachers can simplify the problem of learners in flipped classes by adding some practices relevant to reading comprehension in order to help learners become more proficient in different context. Because class time is just for practicing and problem solving in flipped classes.

However, when learners know why they learn a language, they are more cautious about the ways that facilitate this process. Teachers should provide rich opportunities for learners to engage in active learning while coping with their learning problems according to flipped instructions. Also, it is useful for syllabus designers to have in their mind that students are not the same. They differ in personality and learning styles. At the end, in flipped classroom learners are passive receivers of information so it helps more stressful learners by creating convenient environment in schools and institutes. Offices or organizations dealing with English language can send audio or video lectures to their employees, staff and personnel like airport, tourism organization or travel agencies to learn better without sending too much money and time in classes. This learning strategy may be useful for learners, especially for the lower competency learners, educators because of practicing and watching or listening more and more.

Finally, language learners, who are the core of teaching and learning processes, should realize that learning has various forms. Although the most common form of learning is receiving feedback to help teachers in facing the problem, other peers in the class can also foster the process; it is significant to use them.

Whilst video or audio-enhanced lectures/presentations appear to be common mediums used by educators in flipping their classrooms, there are potential challenges associated with the flipped classroom approach which need to be noted. The flipped classroom may cause students to become quite resistant or concerned, as flipped classes require them to take on more responsibility for their self-learning [12, 19], [28]. Lecturers, tutors or instructors need to be trained on how to effectively structure and implement flipped classrooms which require substantial time and effort for the lecturer [12, 7]. Also, lecturers adopting the flipped approach should ensure they provide relevant, up-to-date resources to better support their flipped lectures. Most importantly, flipped lectures should be carefully tailored for students to prepare them for in-class activities to maximize their learning experiences [19],[28], because striking "a balance between active classroom activities and demonstration/clarification is important" (Butt, 2014, p. 39).

Whilst flipped classrooms can have many benefits for addressing the ways educators teach and the ways in which students learn, certain challenges are associated with the implementation of flipped classrooms. The time-consuming nature of the set-up required for a flipped classroom and student frustration at being responsible for own learning [24] can all contribute toward less-than-successful cases of flipped learning.
Nevertheless, with careful design and implementation, flipped classrooms can play a key role in modernizing education in the higher educator sector, by freeing up more time for lecturers to design learner-centered activities and in turn encourage students to become independent self-learners who are able to apply knowledge and skills to solve real-world problems in their future careers and lives.

As mentioned before, some studies showed that flipped classroom instruction could improve students' achievements compared with the ordinary classroom instruction, on the other hand some studies showed that, the flipped classroom couldn't. Meanwhile, the results of this study are in agreement with prior research [34], which showed that flipping the classroom creates an interactive environment where EFL learners participate actively to learn with and from one another.

As a conclusion from the research study and the literature review of flipped classroom studies, there are many factors could affect the result of applying flipped classroom instruction, like the teacher's readiness and teacher's qualifications, the content, the quality of the videos or audios, the in-class activities, and the student's commitment of seeing the videos or listening them before the classroom. This study may help teachers in the research site for planning and flipping some of their lesson to catch up with curriculum pacing, it may help also in the intervention plans of the weak students, teachers can use flipped classroom to improve the level of students.

\section{References}

[1] Alharbi, A. M. (2015). Building vocabulary for language learning: approach for ESL learners to study new vocabulary. Journal of International Students, 5 (4), 501-511.

[2] Awidi, I. T., \& Paynter, M. (2018). The impact of a flipped classroom approach on student learning experience. Computers and Education, 128, 269-283.

[3] Baker, J. W. (2000) "The 'classroom flip': Using web course management tools to become the guide by the side," 11th International Conference on College Teaching and Learning, Jacksonville, Florida, United States, April 12-15.

[4] Bergmann, J., \& Sams, A. (2012). Flip your classroom: Reach every student in every class every day. Washington, DC; Alexandria, VA: ISTE; ASCD

[5] Bishop, J. L., \& Verleger, M. A. (2013). The flipped classroom: A survey of the research. In ASEE National Conference Proceedings, Atlanta, GA (Vol. 30, No. 9, pp. 1-18).

[6] Boucher, B., Robertson, E., Wainner, R., \& Sanders, B. (2013). "Flipping" Texas State University's physical therapist musculoskeletal curriculum: Implementation of a hybrid learning model. Journal of Physical Therapy Education, 27 (3), 72-77.

[7] Ceylaner, S. G., \& Karakuş, F. (2018). Effects of the Flipped Classroom Model on Students' Self-Directed Learning Readiness and Attitudes Towards the English Course. English Language Teaching. 1 (9), 129-143. 
[8] Cole, J. E. (2009). Strategies for success: Teaching an online course. Rural Special Education Quarterly, 28 (4), 36-40.

[9] Cook, T. D., \& Campbell, D. T. (1979). Quasiexperimentation: Design and analysis issues for field settings. Chicago: Rand McNally

[10] De Jong, T. (2010). Cognitive load theory, educational research, and instructional design: Some food for thought. Instructional Science, 38, 105-134.

[11] Educause, C. (2012). Things you should know about flipped classrooms. Retrieved from http://net.educause.edu/ir/library/pdf/eli7081.pdf.

[12] Finkel, F. (2012, November). Flipping the script in K12. District Administration. Retrieved from http://www.districtadministration.com/article/flipping-script$\mathrm{k} 12$

[13] Fotos, S., \& Browne, C. M. (2004). The development of CALL and current options. In S. Fotos \& C. M. Browne (Eds.), new perspectives on CALL for second language classroom (pp. 3-14). Mahwah, MJ: Lawrence Erlbaum Associates

[14] Fulton, K. (2012). Upside down and inside out: Flip your classroom to improve student learning. Learning \& Leading with Technology, 39 (8), 12-17.

[15] Gallagher, K. (2009). From guest lecturer to assignment consultant: Exploring a new role for the teaching librarian.

[16] Gannod, G. C., Burge, J. E., \& Helmick, M. T. (2008). Using the inverted classroom to teach software engineering. In Proceedings of the 30th international conference on Software engineering (pp. 777-786). ACM.

[17] Gilboy, M. B., Heinerichs, S., \& Pazzaglia, G. (2015). Enhancing student engagement using the flipped classroom. Journal of nutrition education and behavior, 47 (1), 109-114.

[18] Goodwin, B., \& Miller, K. (2013). Teaching self-regulation has long-term benefits. Educational Leadership, 70 (8), 80-8.

[19] Herreid, C., \& Schiller, N. (2013). Case Studies and the Flipped Classroom. Journal of College Science Teaching, 42, 62-66.

[20] Hwang, G. J., T. C. Hsu, C. L. Lai, and C. J. Hsueh. 2017. 'Interaction of problem-based gaming and learning anxiety in language students' English listening performance and progressive behavioral patterns'. Computers \& Education 106: 26-42.

[21] Kirmizi, F. (2010). Relationship between reading comprehension strategy use and daily free reading time. Procedia Social and Behavioral Sciences, 2, 4752-4756.

[22] Lage, M. J., Platt, G. J., \& Treglia, M. (2000). Inverting the classroom: A gateway to creating an inclusive learning environment. The Journal of Economic Education, 31 (1), 3043.

[23] Laman, J. A., Brannon, M. L., \& Mena, I. B. (2012). Classroom flip in a senior-level engineering course and comparison to previous version. In 119th ASEE Annual Conference and Exposition. American Society for Engineering Education.
[24] Millard, E. (2012). Reasons Flipped Classrooms Work: Turning lectures into homework to boost student engagement and increase technology fueled creativity. University Business.com, 26-29.

[25] Milman, N. B. (2012). The flipped classroom strategy: What is it and how can it best be used? Distance Learning, 9 (3) 85.

[26] Nasri, M., \& Biria, R. (2016). Integrating multiple and focused strategies for improving reading comprehension and L2 lexical development of Iranian intermediate EFL learners. International Journal of Applied Linguistics and English Literature, 6 (1), 311-32.

[27] Puskorius, R. (2011). Reading comprehension strategies for elementary students. Retrieved December 1, 2017, from: http://createcomputelearn.com/2013/08/08/comrehensionstrategies/.

[28] Sankey, M. D., \& Hunt, L. (2013). Using technology to enable flipped classrooms whilst sustaining sound pedagogy. In Annual Conference of the Australasian Society for Computers in Learning in Tertiary Education (Vol. 30, pp. 785-795). Sydney: Macquarie University.

[29] Sheu, C. M. (2011). Effects of an online GEPT simulated-test English remedial course on test performance, English language learning strategy us and perceptions. The AsiaPacific Education Researcher, 20 (1), 171-185.

[30] Songhao, H., Saito, K., Maeda, T., \& Kubo, T. (2011). Evolution from Collaborative Learning to Symbiotic ELearning: Creation of New E-Learning Environment for Knowledge Society. Online Submission, 8 (1), 46-53.

[31] Strayer, J. F. (2012). How learning in an inverted classroom influences cooperation, innovation and task orientation. Learning environments research, 15 (2), 171-193.

[32] Sweller, J. (2007). Evolutionary biology and educational psychology. In J. S. Carlson \& J. R. Levin (Eds.), Psychological perspectives on contemporary educational issues (pp. 165-175). Greenwich, CT: Information Age.

[33] Syatriana, E. (2012). Developing the students' reading comprehension through cognitive reading strategies of the first year students of SMAN 16 Makassar. Unpublished Under graduated Thesis.

[34] Tucker, B. (2012). The flipped classroom. Education next, 12 (1), 82-83.

[35] Wixson, K. K., \& Peters, C. W. (1984). Reading redefined: A Michigan Reading Association position paper. The Michigan Reading Journal, 17, 4-7.

[36] Yu, Z. and G. Wang. 2016. 'Academic achievements and satisfaction of the clicker-aided flipped business English writing class'. Educational Technology \& Society 19: 298312.

[37] Zainuddin, Z., \& Perera, C. J. (2017). Exploring students' competence, autonomy and relatedness in the flipped classroom pedagogical model. Journal of Further and Higher Education, 43 (1), 115-126. 